\title{
CONVECTIVE CONDENSATION HEAT TRANSFER OF R134A IN TUBES AT DIFFERENT INCLINATION ANGLES
}

\author{
Adekunle O. Adelaja ${ }^{* * *}$, Jaco Dirker**, Josua P. Meyer* \\ Department of Mechanical and Aeronautical Engineering, University of Pretoria, Pretoria \\ Private Bag X20, Hatfield 0028, South Africa. \\ *Corresponding author: Tel: +27 12420 3104, Email: josua.meyer@up.ac.za \\ **Alternate corresponding author: Tel: +27 12420 2465, Email: jaco.dirker@up.ac.za \\ ***Alternate corresponding author: Email: kunle.adelaja@up.ac.za
}

\begin{abstract}
An experimental study of convective condensation heat transfer of R134a was conducted in an inclined smooth copper tube of inner diameter of $8.38 \mathrm{~mm}$. The test condenser had a straight copper tube section with an effective length of $1.488 \mathrm{~m}$ and was cooled by water circulated in the surrounding annulus in a counter-flow arrangement. The rate of heat transfer was maintained at an average of $250 \mathrm{~W}$ throughout the experiment while the mean vapour qualities ranged between 0.1 and 0.9 , mass flux between $200 \mathrm{~kg} / \mathrm{m}^{2} \mathrm{~s}$ and $400 \mathrm{~kg} / \mathrm{m}^{2} \mathrm{~s}$ for inclination angles varied between $-90^{\circ}$ (vertical downward) and $+90^{\circ}$ (vertical upward) covering the whole range of inclination at saturation temperature of $50^{\circ} \mathrm{C}$. The results show that the inclination angles and mean vapour qualities strongly influence the coefficient of heat transfer and an optimum inclination angle was found to be between $-15^{\circ}$ and $-30^{\circ}$ (downward flow). The developed correlation gave an average and mean deviations of $-3.44 \%$ and $9.22 \%$ respectively for horizontal flow and, 5.25\% and $19.41 \%$ respectively for vertical downward flow.
\end{abstract}

Keywords: experiment; condensation; heat transfer coefficient; inclination angle; smooth tube

\section{INTRODUCTION}

Heat pumps enable a more efficient and effective use of energy and help to recover waste energy in that they inject or recirculate environmental and waste heat into a heat production process and by that considerably reduce the demand for fossil energy as well as the emission of $\mathrm{CO}_{2}$. Thermal energy systems with temperature of $50^{\circ} \mathrm{C}$ and above can be attained by heat pumps and can be used for heating, drying or serve as heat source for absorption or adsorption refrigeration [1, 2]. However, the conventional heat pump system is often restricted to hot water temperature lower than $55^{\circ} \mathrm{C}$ for two reasons. One, it is often used for district and commercial water heating for which higher temperatures are unnecessary. Secondly, increase in the required hot water temperature reduces the coefficient of performance $[3,4]$.

Since the ban on production and consumption of ozone depleting CFCs by different countries following the 1987 Montreal and the 2000 Kyoto protocols, research has concentrated on searching for alternatives and the development of environmentally friendly fluids with no or negligible ozone depleting potential (ODP) and global warming potential (GWP). Also, focus has been on how to improve energy efficiency, heat pump performance and reduce primary energy consumption [5]. The proposed replacements for the CFCs are pure hydrochlorofluoro- cabons (HCFCs), hydrofluorocarbons (HFCs), natural refrigerants (NRs) and zeotropic and azeotropic mixtures of environmentally benign refrigerants [6]. Alternatives for R22 - which has been extensively used as residential heat pump and airconditioning systems for more than five decades are R134a, R404a, R407c, R410a,b, R508 etc. [1, 7, 8]. Hence, studies on condensation and evaporation heat transfer of these alternatives are imperative to ascertain their suitability in heat pumps, though, in this study focus is on condensation heat transfer of one of the alternatives - R134a. 
Comprehensive reviews on convective condensation heat transfer have been carried out $[9,10]$. These reviews show that limited studies have been done on convective condensation of $\mathrm{R} 134 \mathrm{a}$ at saturation temperature of $50^{\circ} \mathrm{C}$ in inclined tubes. At saturation temperature of $50^{\circ} \mathrm{C}$ and above, Cavallini et al. [11] and Sapali and Patil's [12] studies were limited to horizontal investigations of condensation heat transfer of R134a in smooth copper tubes of $8.0 \mathrm{~mm}$ and 8.56 $\mathrm{mm}$ inner diameter respectively at different experimental conditions.

On convective condensation in inclined flow for the whole range of inclination angles, Wurfel et al. [13] explained that since there was an increase in heat transfer coefficient as inclination angle increases, in describing film condensation in turbulent two-phase flow, inclination effects should be considered. Akhavan-Behabadi et al. [14 - 16] in their studies of condensation of R134a in microfin and corrugated tubes of $8.32 \mathrm{~mm}$ and $8.92 \mathrm{~mm}$ inner diameters at low mass fluxes of between $53 \mathrm{~kg} / \mathrm{m}^{2} \mathrm{~s}$ and $253 \mathrm{~kg} / \mathrm{m}^{2} \mathrm{~s}$ and saturation temperature of or less than $38^{\circ} \mathrm{C}$ reported enhanced heat transfer and optimum inclination angle of $+30^{\circ}$ (upward flow). Safari and Naziri [17], in their theoretical study of the heat transfer coefficient of R134a, R141b, and R11 obtained an optimum inclination angle of between $-30^{\circ}$ and $-50^{\circ}$ (downward flow). To be specific, the optimum inclination angle obtained for the condensation of R134a was $30^{\circ}$ (downward flow) at saturation temperature of $30^{\circ} \mathrm{C}$ and Reynolds number of 40000 . Experimental studies carried out by Lyulin et al. [18] on condensation heat transfer of pure ethanol at saturation temperature of $58^{\circ} \mathrm{C}$ showed that heat transfer coefficient reduces with temperature difference increase between the saturation and wall temperatures. The optimum inclination effect reported was between $-15^{\circ}$ and $-35^{\circ}$ (downward flow). Lips and Meyer [19-21], in their studies of condensation heat transfer of R134a at the saturation temperature of $40^{\circ} \mathrm{C}$ revealed that inclination effects is predominant in the gravity controlled region where mass fluxes and mean vapour qualities are low. They also obtained an optimum inclination angle of between $-15^{\circ}$ and $-30^{\circ}$ (downward flow).

It is obvious that test apparatus and operating conditions or assumptions (for the case of theoretical study) influence the varying conclusions of most authors investigating the effect of inclination on flow condensation of refrigerant. Although in the developed countries, HFCs (of which R134a is one) will be phased out by 2030 while ten more years of grace is given to the developing countries, R134a has been used in the study for the following reasons: 1) previous data of the refrigerant is available and necessary for comparison purposes; 2) the principles of change in the flow patterns and heat transfer qualitatively will also be valid for other refrigerants; 3) other refrigerants will be tested once the work on R134a has been completed. The refrigerant R134a has been used as reference for other refrigerants to assume a systematic and logical comparison. This paper therefore aims to investigate the effect of inclination on the thermal characteristics of refrigerant in a smooth tube at high saturation temperatures commensurate to the operational temperature of heat pumps for improved thermal performance. Furthermore, a correlation was developed to predict the experimental data for horizontal and vertical downward flow.

\section{DESCRIPTION OF TEST APPARATUS}

\subsection{Experimental setup}

The experimental rig used for the study was the same test facility on which some previous experiments were conducted by Adelaja et al. [22] and Meyer et al. [23]. An overview is presented in this paper.

The test apparatus as shown in Figure 1 comprised of two cycles namely the vapour-compression- and water- cycles. The vapour compression cycle consisted of two high pressure lines. On one of the high pressure lines was a compressor, an accumulator, an evaporator, an electronic expansion valve (EEV), a pre-condenser, a test- condenser or test section, a post-condenser and necessary instruments for measurements and control such as pressure gauges, a flow meter, thermocouples etc. On the second high pressure line was a condenser - bypass condenser, an EEV with necessary instruments for measurements and control. The compressor used was of hermetically sealed scroll type with a cooling capacity of $10 \mathrm{~kW}$ and suitable for handling R134a.

The test condenser was a $1.488 \mathrm{~m}$ long double pipe counter flow heat exchanger using water as a coolant in the annulus. The refrigerant vapour condensed inside the inner copper tube. The inner tube had an inner diameter of $8.38 \mathrm{~mm}$ and an outer diameter of $9.55 \mathrm{~mm}$ while the annulus had an outer diameter of $15.9 \mathrm{~mm}$. The connections to the test condenser were made of flexible pressure hoses. These enabled the test section to rotate about two fixed hinges. Attaining complete condensation of super-heated refrigerant in the test section was difficult so a pre-condenser and a post- condenser ensured that the dry refrigerant underwent complete condensation before reaching the EEV. The precondenser was used to regulate the inlet vapour quality into the test- condenser where test measurements were carried out whereas the water flow through the post condenser was adjusted such that it ensured that there was complete condensation before the EEV. The flow of R134a vapour in the test section was controlled by manipulating the flow 
rate of refrigerant in the bypass condenser. To ensure that the flow through the test section was fully developed, a straight calming section, 50 diameters long was situated at the entrance.

All temperature measurements were done with T-type thermocouples calibrated against a high precision Pt-100 resistant temperature detector to an accuracy of $0.1{ }^{\circ} \mathrm{C}$. On the test condenser, thermocouples were arranged such that the tube wall temperature could be measured. At each location four thermocouples were installed $90^{\circ}$ to each other around the tube; i.e. top, bottom and two sides. Twenty eight of such thermocouples were installed in small pot holes drilled at seven equal-distant positions on the inner tube of the test section. The pre-, test- and post- condensers were insulated to reduce leakage of heat to the surrounding. Pressure transducers and thermocouples were also installed at both the inlet and outlet of the condensers to measure the state of the refrigerant. Also, the temperatures of the inlet and outlet water in each condenser were measured. Two absolute pressure transducers were connected between the inlet and outlet of the test section so that the absolute pressure recording used was the average of the two pressure readings. The pressure was used as the saturation pressure accurate to $\pm 0.25 \%$ of the full scale. The measured value when used with the condensation curve provided by REFPROP [24] gave the saturation temperature which was verified by direct measurement. The difference in the two values was found to be less than $0.1{ }^{\circ} \mathrm{C}$ at high mass fluxes, $400 \mathrm{~kg} / \mathrm{m}^{2} \mathrm{~s}$ and above, while higher variations were observed at low mass fluxes. This, however, might be due to non-uniformity of the flow particularly at smooth stratified and stratified wavy regions. The pressure drop across the test section was measured by a differential pressure transducer (FP 2000 Sensotec) which was calibrated to an accuracy of $\pm 0.05 \mathrm{kPa}$.

At the inlet and outlet of the test section were two sight glasses, which enabled flow visualization and also served as insulators against axial heat conduction. A high-speed camera was installed at the outlet sight glass and was used to record and document the flow pattern. A uniform Phlox backlight was positioned against the sight glass to enable good colour fidelity due to its evenly distributed light emitting diode (LED) illumination.

Cold and hot water were supplied by $50 \mathrm{~kW}$ heating and $70 \mathrm{~kW}$ cooling dual function heat pumps. It was thermostatically controlled such that the cold and hot water were set to $15^{\circ} \mathrm{C}-25^{\circ} \mathrm{C}$ and $40^{\circ} \mathrm{C}$ respectively. The cold and hot water were stored in two 5000 litre insulated water tanks before supplied to the setup.

\subsection{Test conditions and methods}

The test conditions described in Table 1 give the range of experimental variables used in this study and their uncertainties. Tests were conducted at a saturation temperature of $50^{\circ} \mathrm{C}$ for different angles of inclination of the test section. In most cases, tests were conducted for various mass fluxes $\left(200 \mathrm{~kg} / \mathrm{m}^{2} \mathrm{~s}-400 \mathrm{~kg} / \mathrm{m}^{2} \mathrm{~s}\right)$, for different qualities (0.1-0.9). During the experiment, the test section was maintained at between $230 \mathrm{~W}$ and $270 \mathrm{~W}$. After steady state was assumed to have been reached, the different sensor signals were recorded continuously through the data acquisition

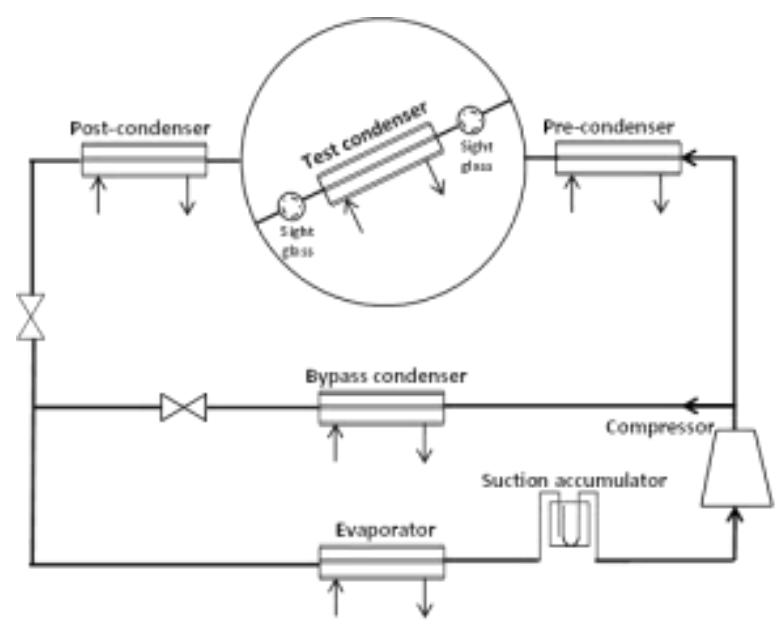

Fig.1. Schematic diagram of experimental set-up. 
Table 1. Experimental variables, range and fluctuations.

\begin{tabular}{|c|c|c|}
\hline Parameter & Range & Fluctuations \\
\hline$T_{\text {sat }}$ & $50^{\circ} \mathrm{C}$ & $\pm 0.6^{\circ} \mathrm{C}$ \\
$G$ & $200-400 \mathrm{~kg} / \mathrm{m}^{2} \mathrm{~s}$ & $\pm 5 \mathrm{~kg} / \mathrm{m}^{2} \mathrm{~s}$ \\
$x_{m}$ & $0.1-0.9$ & \pm 0.01 \\
$\beta$ & $-90^{\circ}$ to $+90^{\circ}$ & $\pm 0.1^{\circ}$ \\
\hline
\end{tabular}

system for about a period of 5 minutes (201 points). In order to avoid noise measurement, the average of the points was used for the calculations of the fluid properties, heat transfer coefficients, and other parameters of interest. The main uncertainties in the heat transfer rate come from the uncertainties in the temperature measurement on the water side, while, on the refrigerant side, it was due to the saturation and wall temperatures. The uncertainties on the mean temperature measurement were approximately $0.1 \mathrm{~K}$ on both water and refrigerant side for each of the stations. Uncertainties in the vapour qualities were lower than \pm 0.03 and that which resulted from the mass flow meters were negligible. However, the uncertainties on the heat transfer coefficient were found to be between $4 \%$ and $9 \%$.

\section{DATA REDUCTION}

Once the temperature, pressure and mass flows of the system reached steady state and the energy balance of the test condenser was stable within 3\%, data was acquired. Eq. (1) was used to calculate the energy balance across the condensers:

$$
E B=\frac{\left|Q_{r e f}-Q_{H_{2} \mathrm{O}}\right|}{Q_{r e f}}
$$

where $Q_{\text {ref }}$ is the heat transfer rate of the refrigerant (total heat loss from the refrigerant in the test line). This was determined from the mass flow rate of the refrigerant and the change in enthalpy between the inlet of the pre-condenser and outlet of the post-condenser. $Q_{\mathrm{H}_{2} \mathrm{O}}$ is the heat transfer rate on the water side and it was obtained from the mass flow rate of the water in the three condensers and the average inlet and outlet temperatures each at the inlet and outlet of the condensers. Temperature and pressure measurements were used to determine the properties of the refrigerants at the entrance of the pre-condenser and at the exit of the post condenser. The thermo-physical properties of the condensing fluid were obtained from these measurements by employing data from a refrigerant property database REFPROP [24]. On the refrigerant side, the enthalpy was obtained at the inlet of the pre-condenser and outlet of the post-condenser utilizing the mass flow rate and the change in enthalpies at these points (eq. 5). The water mass flow rates at the three condensers and the change in temperatures between the inlet and outlet were employed to determine the heat transfer rate of water.

The inlet quality $x_{i n}$ at the test condenser was calculated from the enthalpy of the refrigerant at the inlet of the test section $h_{\text {test, in }}$ and the enthalpies of the liquid $h_{l}$ and vapour $h_{v}$ at the same condition of temperature and pressure as

$$
x_{i n}=\frac{h_{\text {test } \text { in }}-h_{l}}{h_{v}-h_{l}}
$$

The enthalpy of the refrigerant at the inlet of the test section $h_{\text {test }, i n}$, however, was calculated from the enthalpy at the inlet of the pre-condenser $h_{p r e, i n}$ (obtained using the temperature and the pressure condition at the inlet of the precondenser), the heat transfer rate $Q_{p r e}$ and the refrigerant mass flow rate, $\dot{m}_{r e f}$ in the pre-condenser.

$$
h_{\text {test, in }}=h_{\text {pre,in }}-\frac{\left|Q_{\text {pre }}\right|}{\dot{m}_{\text {ref }}}
$$

The heat transfer through the pre-condenser was calculated from the water mass flow rate $\dot{m}_{\mathrm{H}_{2} \mathrm{O} \text {, pre }}$, the specific heat capacity $c_{p}$ and the inlet $T_{p r e, \text { in }}$ and outlet $T_{\text {pre,out }}$ temperatures

$$
Q_{\text {pre }}=\dot{m}_{\mathrm{H}_{2} \mathrm{O}, \mathrm{pre}} c_{p}\left(T_{\text {pre,in }}-T_{\text {preout }}\right)
$$


The vapour quality at the exit of the test section was calculated by replacing the enthalpy at the inlet $h_{\text {test }, \text { in }}$ by the enthalpy at the outlet $h_{\text {test,out }}$ in eq. (2) at the refrigerant saturation temperature and pressure. The enthalpy at the outlet of the test section is however calculated thus

$$
h_{\text {test,out }}=h_{\text {test, in }}-\frac{\left|Q_{\text {test }}\right|}{\dot{m}_{\text {ref }}}
$$

The heat flow $Q_{\text {test }}$ through the test condenser was obtained by replacing the mass flow rate, specific heat capacity and the inlet and outlet temperatures in eq. (4) by these same parameters at the test section conditions. The mean vapour quality of the test section was obtained from the arithmetic mean of the inlet and outlet qualities: $x_{m}=\left(x_{\text {in }}+x_{\text {out }}\right) / 2$. The convective heat transfer coefficient in the test condenser was calculated from the Newton's law of condensation thus:

$$
\alpha_{\text {cond }}=\left|\frac{Q_{\text {test }}}{A\left(\bar{T}_{w, i}-T_{\text {sat }}\right)}\right|
$$

where $A$ is the inner surface area of the inner tube of the test condenser, $T_{\text {sat }}$ is the mean of the saturation temperature at the inlet and outlet of the section. $\bar{T}_{w, i}$ is the mean inner wall temperature and it is related to the measured mean outer wall temperature of the tube $\bar{T}_{w, o}$ through the thermal resistance of the wall of the copper tube, $R_{w}$

$$
\bar{T}_{w, i}=\bar{T}_{w, o}+\left|Q_{t e s t} R_{w}\right|
$$

where $R_{w}=\ln \left(d_{o} / d_{i}\right) / 2 \pi k_{C u} L$ and $\bar{T}_{w, o}$ was calculated using the trapezoidal numerical integration:

$$
\bar{T}_{w, o}=\frac{1}{L} \sum_{j=1}^{6}\left[\left(T_{w, o}^{j}+T_{w, o}^{j+1}\right)\left(z_{j+1}-z_{j}\right)\right]
$$

where $T_{w, o}^{j}$ is the average temperature at the $j^{\text {th }}$ location of the seven different stations and $z_{j+1}-z_{j}$ is the distance between the measurement locations.

Figure 2 shows the test matrix of the thirteen experimental data conditions used in the present experiment on El Hajal et al. [25] flow pattern map. The matrix shows that most of the flow patterns are within the annular and stratified-wavy regimes.

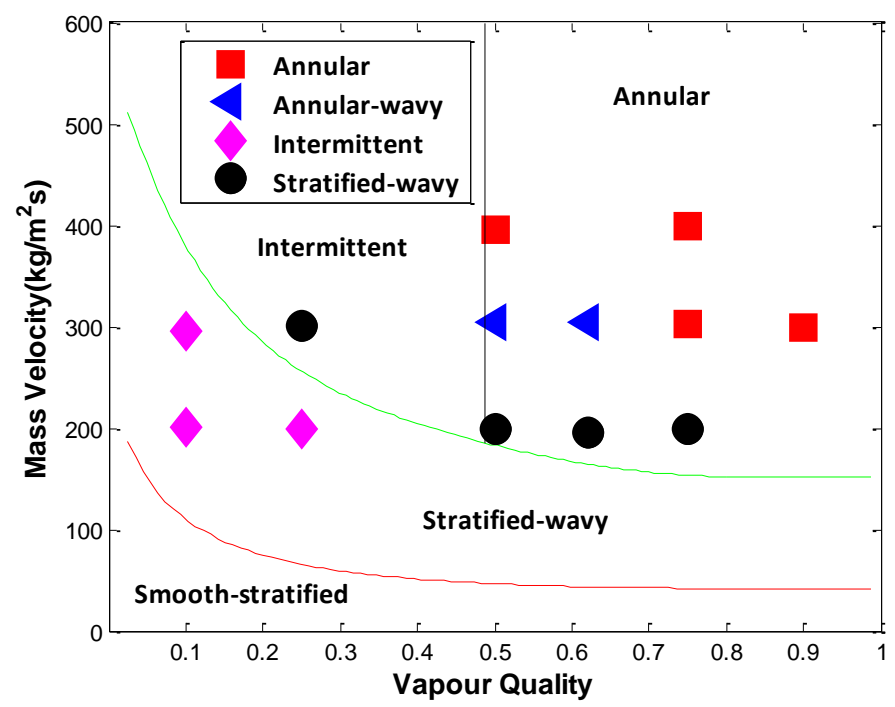

Fig. 2. Experimental test matrix for horizontal flow on the El Hajal et al. [25] flow pattern map. 


\section{RESULTS AND DISCUSSION}

The condensation heat transfer coefficients of HFC-134a were obtained for around 169 experimental data points.

\subsection{Flow Patterns, Flow Pattern Map and Transition Criteria}

Two-phase flow pattern in smooth tubes occur as a result of the interaction of the gravitational, shear and capillary forces between the liquid and vapour phases. These combined forces impose some peculiar features on the flow distribution. The flow patterns were captured with the aid of a high-speed video camera, which was installed to view the flow distribution through a sight glass located at the exit of the test section. The flow patterns observed were categorised into five types based on Kim and Ghajar's [26] classification. They are stratified-wavy, annular-wavy, annular, intermittent and churn flows. Churn flow comprises the bubbly/slug and annular/bubbly/slug. Intermittent flow comprises slug, plug and elongated bubble flows [27].

From Fig 3, Stratified-wavy ensues during slightly downward orientation. Liquid is mostly located at the bottom of the tube and there are waves at the liquid-vapour interface. Annular- wavy flow occurs when the velocity of the vapour is increased (i.e. mass flux) leading to more condensate accumulating at the top of the tube. Annular flow occurs due to high vapour velocity so that the liquid is located uniformly or near uniformly at the perimeter of the tube. During intermittent flow, the wave tips are able to reach the upper surface of the tube. It also occurs when vapour velocity is so low that vapour is trapped in the liquid. Churn flow occurs mainly during or near vertical orientations (either upward or downward). It is the result of slugs of liquid collapsing into the centre of the vapour.

Figure 4 shows the flow patterns as they varied with inclination angle and vapour quality for $G=300 \mathrm{~kg} / \mathrm{m}^{2} \mathrm{~s}$ and $T_{\text {sat }}$ $=50^{\circ} \mathrm{C}$. The figure reveals that flow pattern is dependent on inclination angle and mean vapour quality. At $x_{m}=0.1$, the flow was basically intermittent, though, it transits between intermittent and stratified-wavy. At the vertical upward and downward, churn flow was present. As the quality increased, the flow tended toward annular flow because of the increase in the shear force. For $x_{m}=0.25$ and 0.5 , during downward flow, the liquid film became thinner with $\beta$ but the converse was the case during upwards flow. At $\beta=+60^{\circ}$, the flow became intermittent and then churn flow during both vertical upward and downward flows. For $x_{m}=0.75$ and 0.9 , the flow was annular irrespective of the tube orientation. Figure 5 shows the variation of the flow pattern with inclination angle for different mass fluxes for $x_{m}=$ 0.5 . For $G=200 \mathrm{~kg} / \mathrm{m}^{2} \mathrm{~s}$, the result reveals that the flow was stratified-wavy for most of the orientations but became intermittent for $\beta=+60^{\circ}$, then churn flow during the vertical orientations. As $G$ increased, the flow tends toward annular flow. For $G=300 \mathrm{~kg} / \mathrm{m}^{2} \mathrm{~s}$, the flow was annular-wavy and annular for $G=400 \mathrm{~kg} / \mathrm{m}^{2} \mathrm{~s}$.

The heat transfer in two-phase flow is strongly influenced by the flow pattern and so, before considering the heat transfer characteristics, the flow patterns are compared with El Hajal -Thome - Cavallini [25] flow map, Soliman [28] and Dobson and Chato [29] criteria.

Figure 2 displays the flow pattern observed during the experiment in comparison with the predictions of the flow pattern map of El Hajal -Thome - Cavallini [25] for the horizontal flow. The results show a good agreement apart from the pattern observed for $x_{m}=0.1$ for $G=200 \mathrm{~kg} / \mathrm{m}^{2} \mathrm{~s}$. The other data points that were not well predicted were close to the transition between the different flow patterns.

The Soliman criteria characterizes flow pattern into basically two regions; the stratified-wavy and annular (which includes mist flow) based on Froude dimensionless number, $F r_{s o}$. When $F r_{s o}<7$ the flow is judged to be stratifiedwavy flow but when greater, it is considered as annular flow. Dobson and Chato [29] modified the Soliman criteria to accommodate the intermittent flow region. In their adaptation, $F r_{s o}<7$ also denoted stratified-wavy, $7<F r_{s o}<18$ was intermittent while $F r_{s o}>18$ was regarded as annular flow.

In Figure 6, the present data points were presented for some inclined angles. The Soliman Froude dimensionless number values were presented for different mass fluxes and mean vapour qualities at saturation temperature of $50^{\circ} \mathrm{C}$. The Soliman and Dobson and Chato criteria are displayed in the figures. Taking into consideration the Soliman criteria, the figure reveals that majority of the experimental data should be annular. Meanwhile, using the Dobson and Chato criteria, less than $50 \%$ of the data falls within the annular range for the horizontal flow (Figure 6a). Comparing the two criteria with the analysis of the experimental videos and visual observations, Soliman criteria proves inadequate whereas Dobson and Chato criteria agree with the flow patterns of the experimental data. Exploring the Dobson and Chato criteria for horizontal flow, experimental data for $x_{m} \geq 0.5, G=400 \mathrm{~kg} / \mathrm{m}^{2} \mathrm{~s}, x_{m} \geq 0.62$ for $G=300 \mathrm{~kg} / \mathrm{m}^{2} \mathrm{~s}$ and $x_{m}$ $\geq 0.75$ for $G=200 \mathrm{~kg} / \mathrm{m}^{2} \mathrm{~s}$ are included in the annular flow. For intermittent flow, data for $x_{m}=0.5, G=300 \mathrm{~kg} / \mathrm{m}^{2} \mathrm{~s}$ and $x_{m}=0.5$ and $x_{m}=0.62$ for $G=200 \mathrm{~kg} / \mathrm{m}^{2} \mathrm{~s}$ are included. Whereas data for $x_{m}=0.1$ and $x_{m}=0.25$ for $G=$ $200 \mathrm{~kg} / \mathrm{m}^{2} \mathrm{~s}$ and $300 \mathrm{~kg} / \mathrm{m}^{2} \mathrm{~s}$ are included in the wavy flow region. Apart from the data points for $x_{m}=0.1$ for mass velocity of $G=200 \mathrm{~kg} / \mathrm{m}^{2} \mathrm{~s}$ and $G=300 \mathrm{~kg} / \mathrm{m}^{2} \mathrm{~s}$, other data are in agreement seeing that the two other points that are 
not well predicted (i.e. $x_{m}=0.5$ for $G=300 \mathrm{~kg} / \mathrm{m}^{2} \mathrm{~s}$ and $x_{m}=0.75$ for $G=200 \mathrm{~kg} / \mathrm{m}^{2} \mathrm{~s}$ ) were close to the transition between the flow

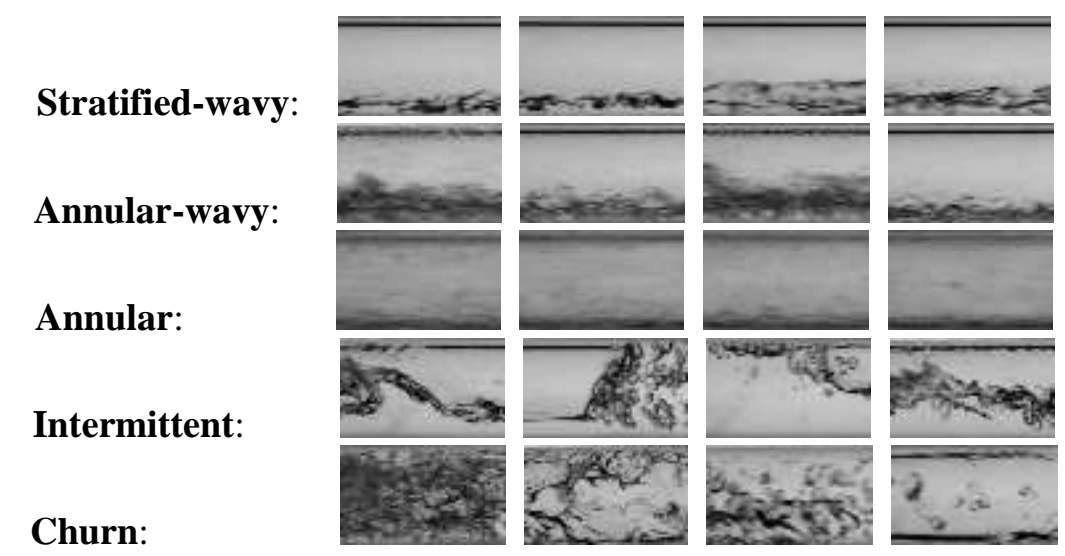

Fig. 3. The different types of flow patterns observed during this study.

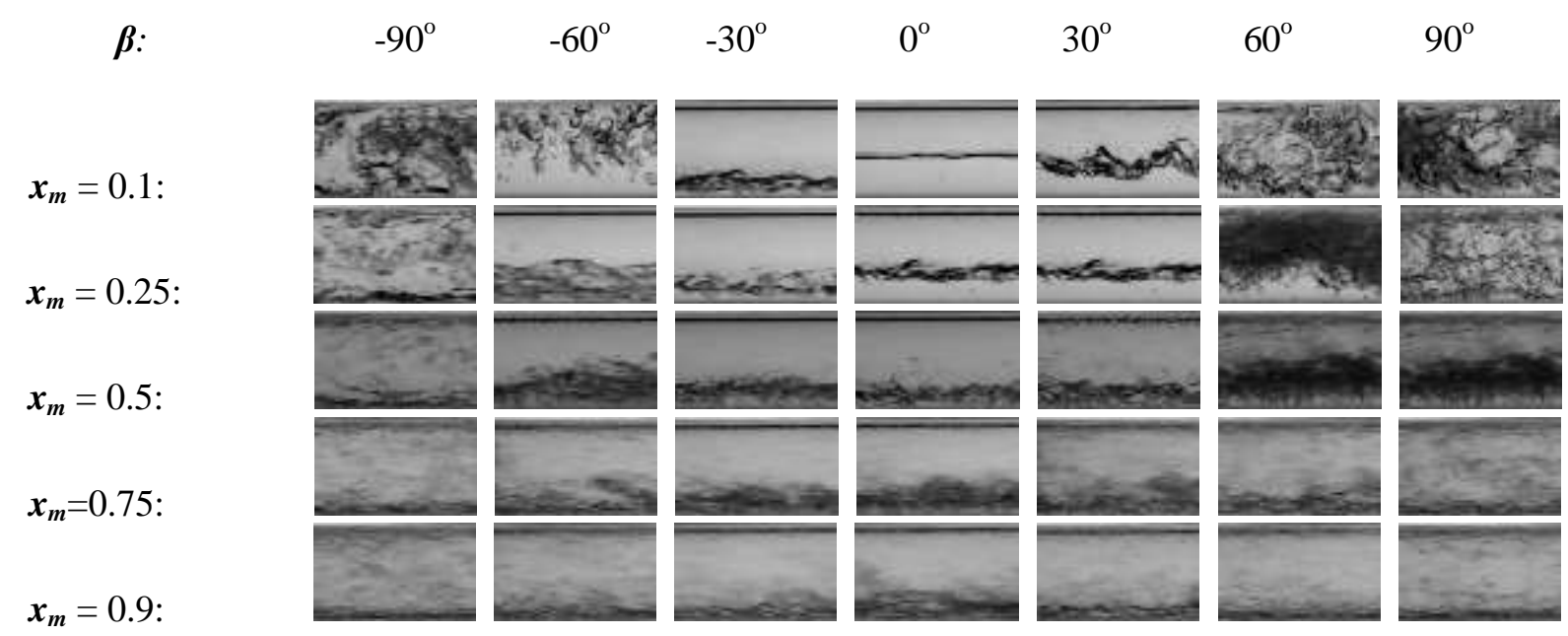

Fig. 4. Effect of the inclination angle on the flow pattern for different $x_{m}$ for $G=300 \mathrm{~kg} / \mathrm{m}^{2} \mathrm{~s}, T_{s a t}=50^{\circ} \mathrm{C}$.

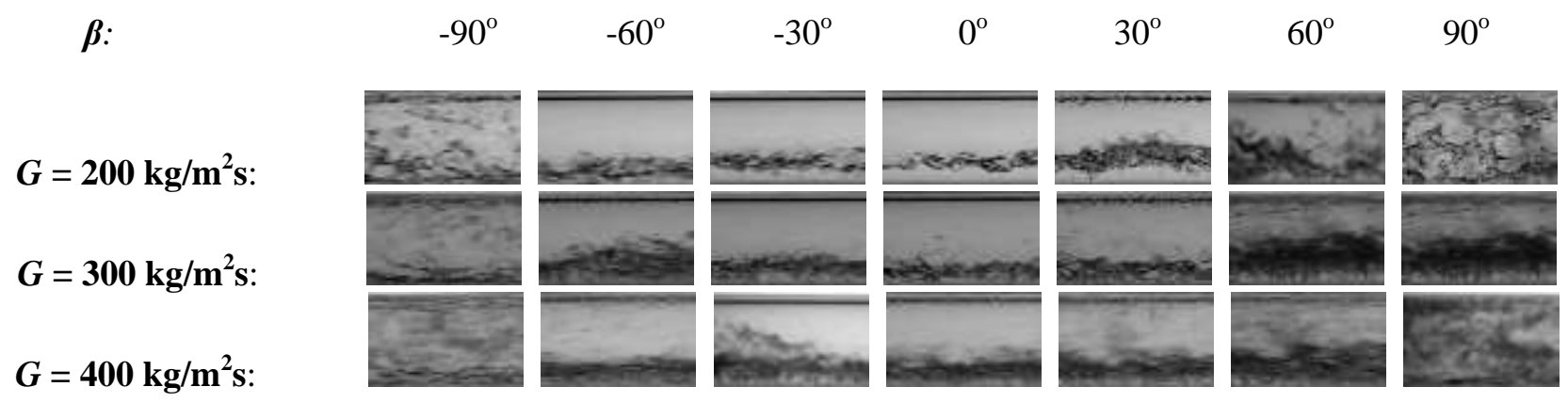

Fig. 5. Effect of the inclination angle on the flow pattern for different $G$ for $x_{m}=0.5, T_{s a t}=50^{\circ} \mathrm{C}$.

patterns. Experimental data for other orientations were also shown in Figure $6 \mathrm{~b}-\mathrm{g}$, however, more experimental data are needed to ascertain the accuracy of the criteria. 


\subsection{Condensation Heat Transfer}

The condensation heat transfer data are shown in Figure 7 to Figure 10. In order to check the reliability of the data it was essential to compare the experimental data for a horizontal tube with well-established correlations in the literature. Figure $7 \mathrm{a}$ presents the Nusselt number obtained for the present experimental results compared with some existing condensation correlations as well as the correlation which fits the data obtained from our experiment. For the horizontal flow, the correlations of Shah [30], Dobson and Chato [29] and Jung et al. [31] over predicted the data in the annular flow region while the correlations of Shah [30] and El Hajal et al. [25] under predicted the data within the low quality region. However, the correlation of Cavallini et al. [32] predicted all the data within $\pm 30 \%$. From this, it was concluded that the data set was acceptable. From analysis, Shah [30], Dobson and Chato [29], Jung et al. [31], El Hajal et al. [25] and Cavallini et al. [32] display average deviations of $20.65 \%, 31.17 \%, 26.21 \%,-4.94 \%$ and $12.46 \%$, respectively. The mean deviations are $25.51 \%, 32.47 \%, 27.81 \%, 19.52 \%$ and $14.99 \%$ respectively. For vertical downward flow, Figure $7 \mathrm{~b}$, the data were compared with notable downward correlations. All the correlations considered over predicted the data at the high vapour quality region and under estimated them at the low quality. The correlations of Shah [30], Dobson and Chato [29], Jung et al. [31] and Kim and Ghajar [26] show mean deviations of $34 \%, 39.5 \%, 39.14 \%$ and above $50 \%$ respectively with average deviations between $27 \%$ and $36 \%$. However, there is need to formulate a better correlation which can both predict the test data within more reasonable and acceptable ranges.

With respect to the refrigerant mass velocity (Figure 8), there is an increase in the heat transfer coefficient as the mass velocity increases. The effect of inclination angle was noticed when $G=200 \mathrm{~kg} / \mathrm{m}^{2} \mathrm{~s}$ and $G=300 \mathrm{~kg} / \mathrm{m}^{2} \mathrm{~s}$. This is when the gravitational effect is predominant compared with the shear stress and capillary actions. Obviously, the inclination effect on the heat transfer coefficient peaked when the angle of inclination was $-30^{\circ}$ (downward flow) for both mass velocities. For $G=400 \mathrm{~kg} / \mathrm{m}^{2} \mathrm{~s}$ the shear force is prevalent and so the effect of inclination seems to be less hence the flow tends to be annular. The effect of inclination is clearly shown in Figure 9, when $200 \leq G \leq 340 \mathrm{~kg} / \mathrm{m}^{2} \mathrm{~s}$, the optimum inclination angle is between $-15^{\circ}$ and $-30^{\circ}$ (downward flow). For $G=400 \mathrm{~kg} / \mathrm{m}^{2} \mathrm{~s}$, inclination effect decreases and the shear effect takes the leading role. A minimum heat transfer however is likewise obtained when $\beta=-90^{\circ}$ (downward flow) for $G=200 \mathrm{~kg} / \mathrm{m}^{2} \mathrm{~s}$ and $G=300 \mathrm{~kg} / \mathrm{m}^{2} \mathrm{~s}$ and $\beta=+60^{\circ}$ (upward flow) for $G=400 \mathrm{~kg} / \mathrm{m}^{2} \mathrm{~s}$. This is due to the increment in the film thickness on the wall of the tube. This liquid layer increases the thermal resistance that results in low coefficient of heat transfer. Figure 10 illustrates the effects of inclination and mean vapour quality on the condensation heat transfer for $G=300 \mathrm{~kg} / \mathrm{m}^{2} \mathrm{~s}$ at different flow orientations. Inclination effect is observed when $0.1 \leq$ $x_{m} \leq 0.5$ and the optimum angle at $-15^{\circ}$ and $-30^{\circ}$ (downward flows).

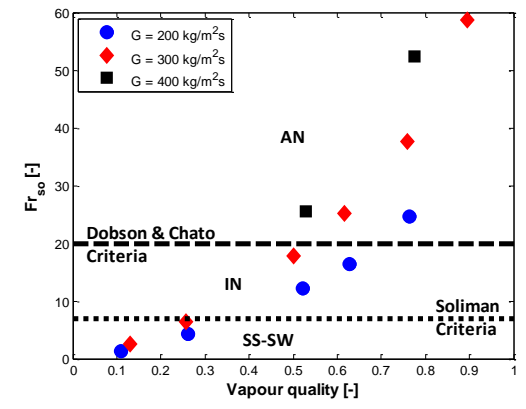

a) $\beta=0^{\circ}$

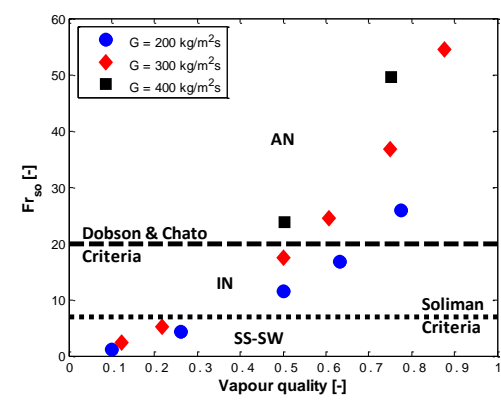

b) $\beta=-90^{\circ}$

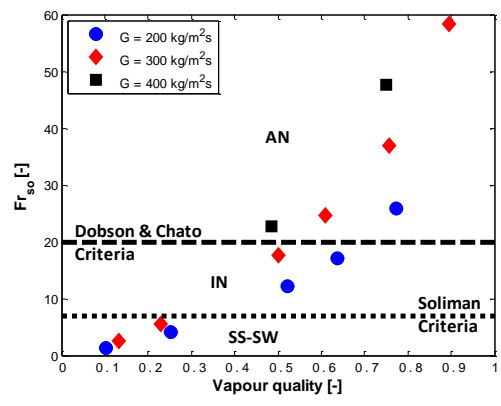

c) $\beta=-60^{\circ}$ 


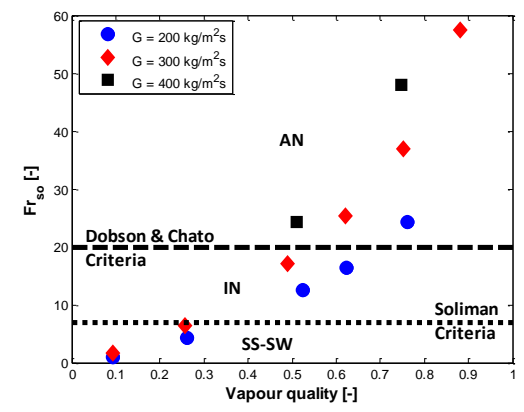

d) $\beta=+60^{\circ}$

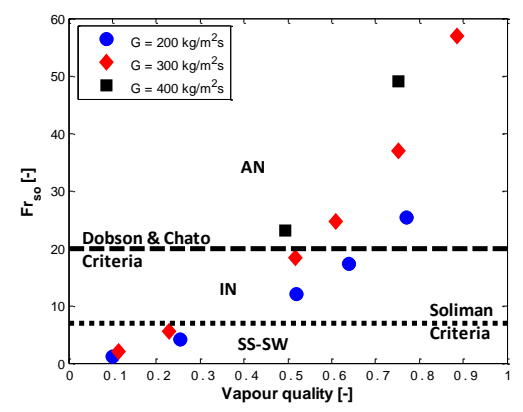

e) $\beta=-30^{\circ}$

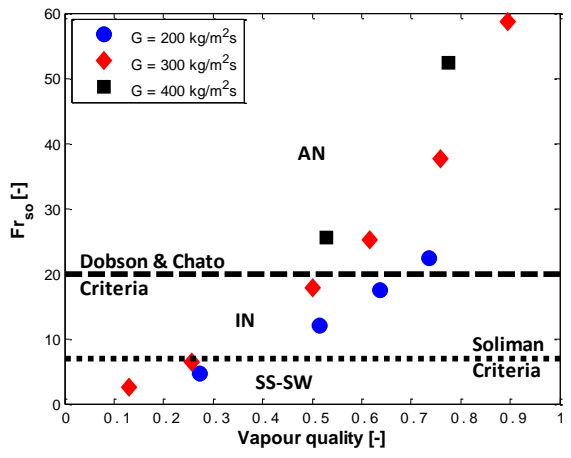

g) $\beta=+90^{\circ}$

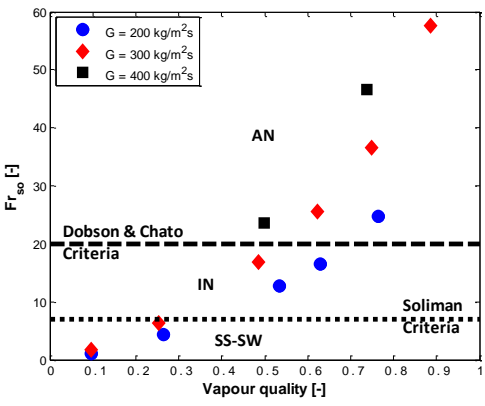

f) $\beta=+30^{\circ}$

Fig. 6. Comparison of experimental data with Soliman [28] and Dobson and Chato [29] criteria for different mass fluxes and mean vapour qualities for inclination angles of a) $0^{\circ}$, b) $-90^{\circ}$, c) $-60^{\circ}$, d) $+60^{\circ}$, e) $-30^{\circ}$, f) $+30^{\circ}$ and g) $90^{\circ}$.

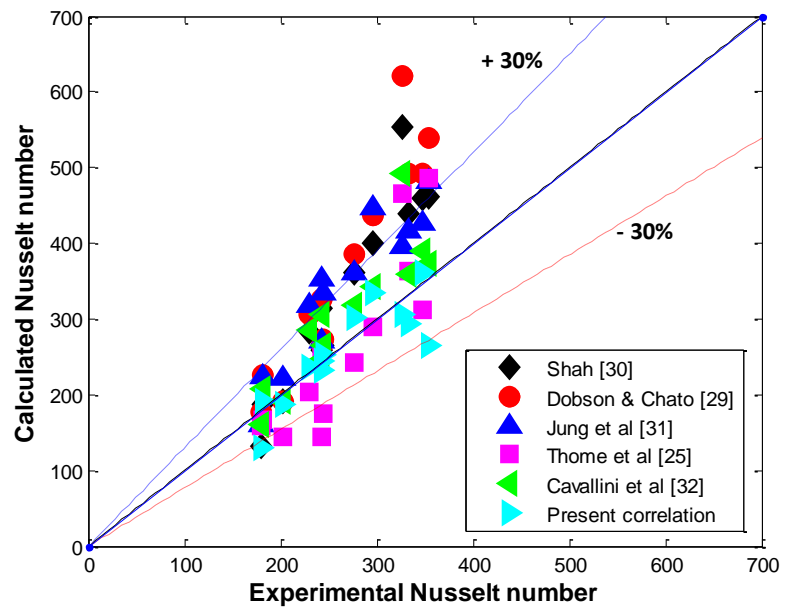

Fig. 7a: Horizontal heat transfer coefficient for $G=200-400 \mathrm{~kg} / \mathrm{m}^{2}$ s for case $T_{\text {sat }}=50^{\circ} \mathrm{C}$. 


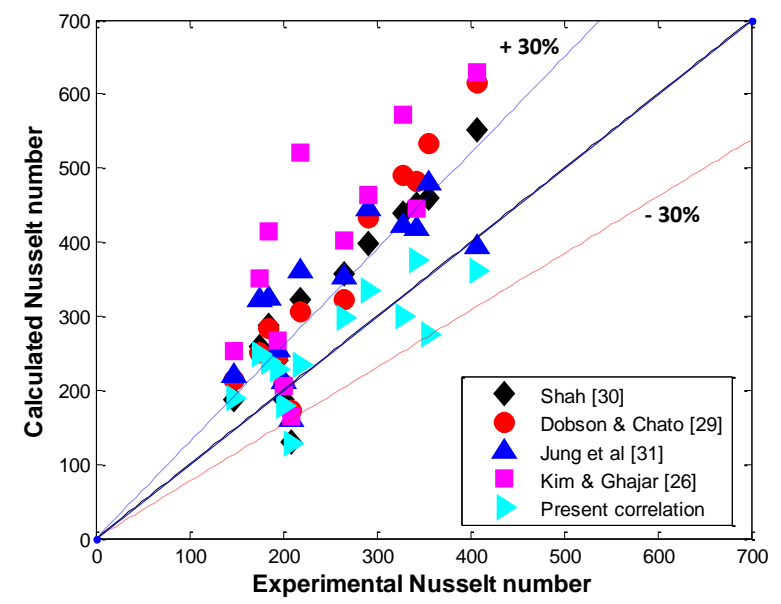

Fig. 7b: Vertical downward heat transfer coefficient for $G=200-400 \mathrm{~kg} / \mathrm{m}^{2}$ s for case $T_{\text {sat }}=50^{\circ} \mathrm{C}$.

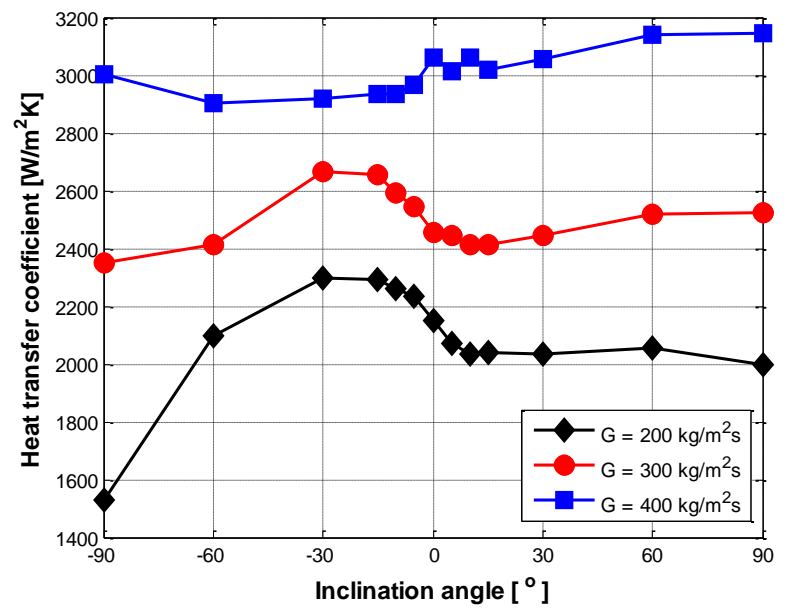

Fig. 8. Inclination effect on heat transfer coefficient for different $G$ for case $T_{\text {sat }}=50^{\circ} \mathrm{C}, x_{m}=0.5$.

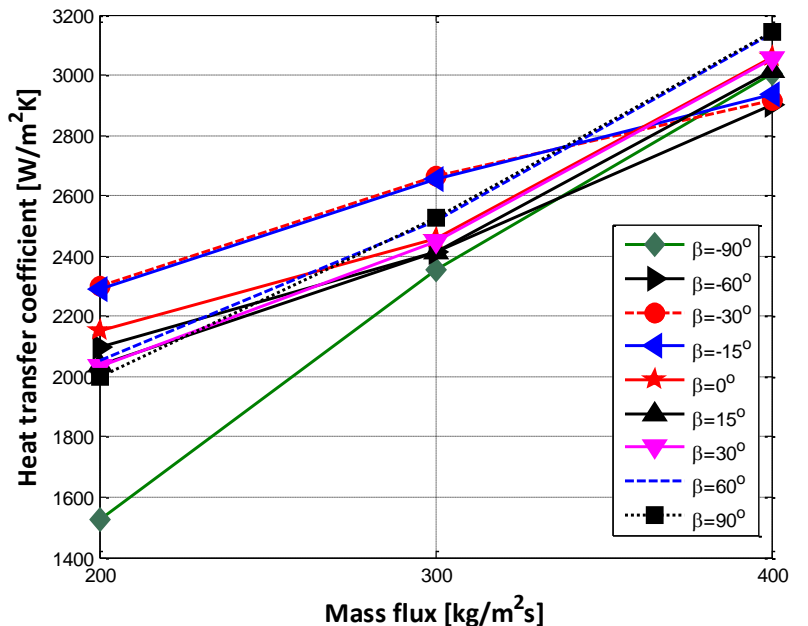

Fig. 9. Effect of $G$ on heat transfer coefficient for different $\beta$ for $T_{\text {sat }}=50^{\circ} \mathrm{C}, x_{m}=0.5$. 


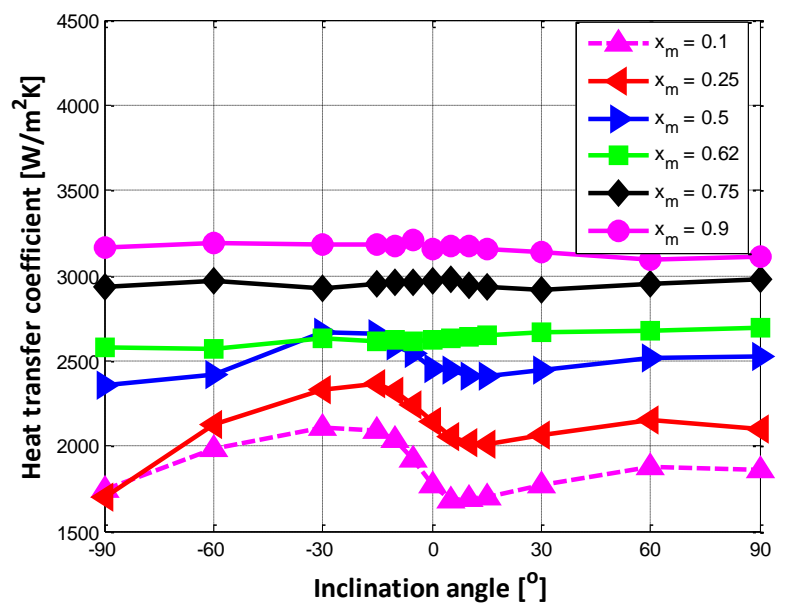

Fig. 10: Inclination effect on heat transfer coefficient for different $x_{m}$ for $G=300 \mathrm{~kg} / \mathrm{m}^{2} \mathrm{~s}$ for $T_{\text {sat }}=50^{\circ} \mathrm{C}$.

\subsection{Development of new correlation}

From the comparison highlighted in the previous section, it can be easily seen that there is need for a better correlation that will predict our experimental data at saturation temperature of $50^{\circ} \mathrm{C}$. This was done by modifying the correlation of Jung et al. [31] as follows:

$$
\frac{N u_{T P}}{N u}=1.03 \chi_{t t}^{-0.56} H M F R^{0.2}
$$

where,

$$
\begin{aligned}
& N u=0.023 \operatorname{Re}_{l}^{0.8} \operatorname{Pr}_{l}^{0.4} \\
& \operatorname{Re}_{l}=\frac{G d(1-x)}{\mu_{l}} \\
& \operatorname{Pr}_{l}=\frac{\mu_{l} C_{p_{l}}}{k_{l}} \\
& \chi_{t t}=\left(\frac{1-x}{x}\right)^{0.9}\left(\frac{\rho_{v}}{\rho_{l}}\right)^{0.5}\left(\frac{\mu_{l}}{\mu_{v}}\right)^{0.1} \\
& H M F R=\left(\frac{Q / A}{G h_{f g}}\right)
\end{aligned}
$$

The new correlation was obtained by fitting our experimental data with the Martinelli's parameter and the HMFR using linear programming technique - multiple regression. The HMFR is termed the heat to mass flux ratio. The constants $1.03,-0.56$ and 0.2 are the constant, and exponents of the Martinelli's parameter and HMFR respectively. Figures $7 \mathrm{a}$ and $7 \mathrm{~b}$ display the well-established correlations for both horizontal and downward vertical flow and the developed correlation. The formulated correlation gives an average and mean deviations of $-3.44 \%$ and $9.22 \%$ respectively, for horizontal flow and $5.25 \%$ and 
$19.41 \%$ respectively, for vertical downward flow. This is an improvement when compared with Jung et al. [31] however; more work still has to be done to fine-tune it to achieve a better result especially, for orientations other than horizontal.

\section{CONCLUSIONS}

For a better understanding of two-phase flow, convective condensation heat transfer of R134a in tubes at different inclination angles have been studied. Local heat transfer coefficients were measured for $\mathrm{R} 134 \mathrm{a}$ in an inclined smooth tube at an average saturation temperature of $50^{\circ} \mathrm{C}$. The heat transfer coefficient increases with mass velocity and vapour quality and, inclination effect was seen to be pronounced at low vapour qualities and low mass velocities. The optimum inclination angle was found to be between $-15^{\circ}$ and $-30^{\circ}$ (downward flow). Based on this, it is expected that heat pump condensers tubes at inclinations of between these angles will have improved thermal operations. The flow pattern maps of El Hajal et al. and Dobson and Chato give good prediction however; there is need for better predictive tools.

The new correlation was developed by modifying the Jung et al. [31] correlation. The correlation showed average and mean deviations of $-3.44 \%$ and $9.22 \%$ respectively for horizontal flow and $5.25 \%$ and $19.41 \%$ respectively for downward flow.

\section{ACKNOWLEDGEMENT}

The funding obtained from the NRF, TESP, University of Stellenbosch/ University of Pretoria, SANERI/SANEDI, CSIR, EEDSM Hub and NAC is acknowledged and duly appreciated.

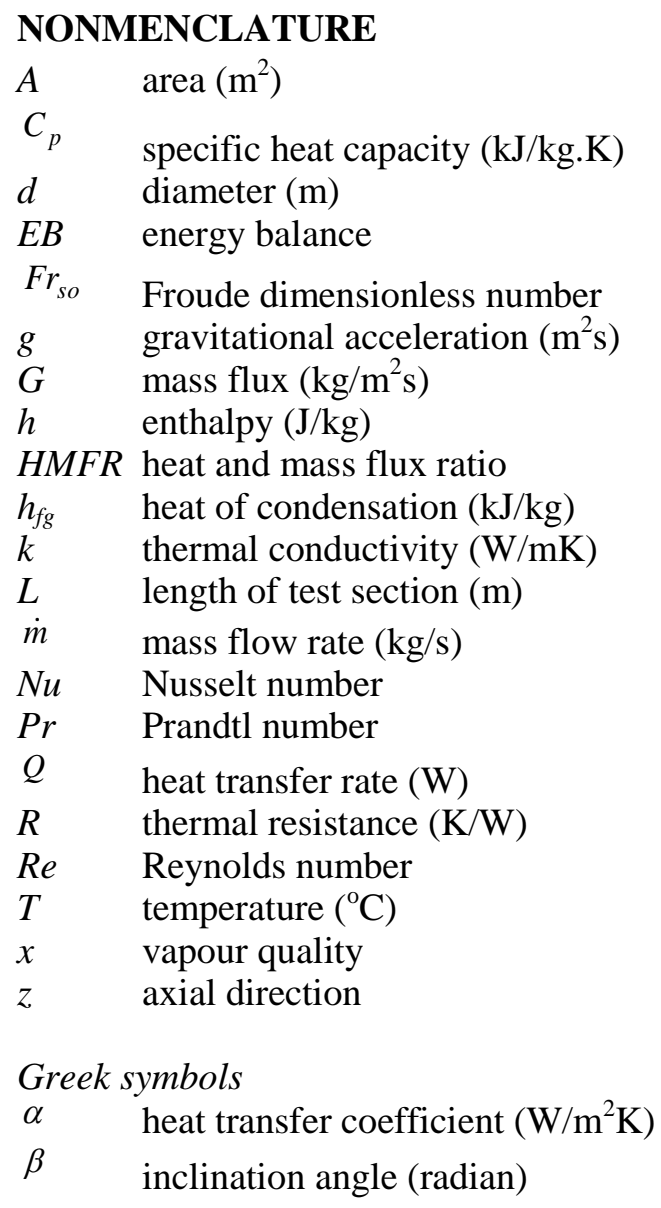




$$
\begin{array}{ll}
\chi_{t t} & \text { Martinelli parameter } \\
\mu & \text { viscosity }(\mathrm{Pa} . \mathrm{s}) \\
\rho & \text { density }\left(\mathrm{kg} / \mathrm{m}^{3}\right)
\end{array}
$$

\begin{tabular}{ll}
\multicolumn{2}{l}{ Subscripts } \\
$\mathrm{Cu}$ & copper \\
$\mathrm{H}_{2} \mathrm{O}$ & water \\
$i$ & inner \\
in & inlet \\
$j$ & measurement location \\
$l$ & saturation liquid \\
in & inner \\
out & outer \\
pre & pre-condenser \\
ref & refrigerant \\
sat & saturation \\
test & test-condenser \\
TP & two-phase \\
$v$ & saturated vapour \\
$w$ & wall
\end{tabular}

\section{REFERENCE}

[1] T. X. Li, H. K. Guo and R. Z. Wang, "High temperature water heat pump with non-azeotropic refrigerant mixture HCFC-22/ HCFC-141b," Energy Convers. Manage., vol. 43, pp. 2033 - 40, 2002 .

[2] Y. Hwang and R. Radermacher, "Experimental evaluation of $\mathrm{CO}_{2}$ water heater," Refrigeration Sci. Technol. Proc., vol. 4, pp. 368 - 75, 1998.

[3] P. Neksa, H. Rekstad, G. R. Zakeri and P.A. Schiefloe, " $\mathrm{CO}_{2}$ heat pump water heater: characteristics, system design and experimental results," Int. J. Refrigeration, vol. 21, pp. 172 - 9, 1998.

[4] P. Neksa, "CO 2 heat pump systems," Int. J. Refrigeration vol. 25, pp. 421 - 7, 2002.

[5] N. Churi and L.E.K. Achenie, "The optimal design of refrigerant mixtures for a two-evaporator refrigeration system," Comput. Chem. Eng., vol. 21, pp. 349 - 54, 1997.

[6] S. Karagoz, M. Yilmaz, O. Comakli and O. Ozyurt, "R134a and various mixtures of R22/ R134a as an alternative to R22 in a vapour compression heat pumps," Energy Convers. Manage., vol. 45, pp. 181 - 96, 2004.

[7] A. Cavallini, "Working fluid for mechanical refrigeration, review paper," Int. J. Refrigeration vol. 19, no. 8, pp. $485-96,1996$.

[8] D. Jung, Y. Song and B. Park, "Performance des mélanges de frigorigenes utilizes pour remplacer le HCFC22," Int. J. Refrigeration, vol.23, pp. 466 - 74, 2000.

[9] A. Cavallini, G. Censi, D. Del Col, L. Doretti, G. A. Longo, L. Rossetto and C. Zilio, "Condensation inside and outside smooth and enhanced tubes- a review of recent research," Int. J. Refrigeration, vol. 26, pp. 373 - 392, 2003.

[10] S. Lips and J.P. Meyer, "Two-phase flow in inclined tubes with specific reference to condensation: a review". Int. J. Multiphase Flow, vol. 37, pp. 845 - 859, 2011.

[11] A. Cavallini, G. Censi, D. Del Col, L. Doretti, G.A. Longo and L. Ressetto, "Experimental investigation on condensation heat transfer and pressure drop of new HFC refrigerants (R134a, R125, R32, R410a, R236ea) in a horizontal smooth tube," Int. J. Refrigeration, vol. 24, pp. 73 - 87, 2001.

[12] S.N. Sapali and P.A. Patil, "Heat transfer during condensation of HFC 134a and R404a inside of a horizontal smooth and micro-fin tube," Exp. Therm. Fluid Sci., vol. 34, pp. 1133-1141, 2010.

[13] R. Wurfel, T. Kreutzer and W. Fratzscher, "Turbulence transfer processes in adiabatic and condensing film flow in inclined tube," Chem. Eng. Technol., vol. 26, pp. 439 - 448, 2003.

[14] M.A. Akhavan-Behabadi, R. Kumar and S.G. Mohseni, "Condensation heat transfer of R 134a inside a microfin tube with different tube inclinations," Int. J. Heat Mass Transf. vol. 50, pp. 4864 - 4871, 2007.

[15] S.G. Mohseni and M.A. Akhavan-Behabadi, "Visual study of flow patterns during condensation inside a microfin tube with different inclinations," Int. Commun. Heat Mass Transf., vol. 38, pp. 1156 - 1161, 2011. 
[16] D. Khoeini, M.A. Akhavan-Behabadi and A. Saboonchi, "Experimental study of condensation heat transfer of R134a flow in corrugated tubes with different inclinations," Int. Commun. Heat Mass Transf., vol. 39, pp. 138 143, 2012.

[17] H. Safari and V. Naziri, "Theoretical modelling and numerical solutions of stratified condensation in inclined tubes," J. Mech. Sci. Technol., vol. 24, pp. 2587 - 2596, 2010.

[18] Y. Lyulin, I. Marchuk, S. Chikov and O. Kabov, "Experimental study of laminar convective condensation of pure vapour inside an inclined circular tube," Microgravity Sci. Technol., vol. 23, pp. 439 - 445, 2011.

[19] S. Lips and P.J. Meyer, "Experimental study of convective condensation in an inclined smooth tube. Part 1: Inclination effect on flow pattern and heat transfer coefficient," Int. J. Heat Mass Transf., vol. 55, pp. 395 - 404, 2012a.

[20] S. Lips and P.J. Meyer, "Experimental study of convective condensation in an inclined smooth tube. Part II: Inclination effect on pressure drops and void fractions," Int. J. Heat Mass Transf., vol. 55, pp. 405 - 412, 2012 b.

[21] S. Lips and P.J. Meyer, "Stratified flow model for convective condensation in an inclined tube," Int. J. Heat Fluid Flow, vol. 36, pp. 83 - 91, 2012c.

[22] A.O. Adelaja, J. Dirker and J.P. Meyer, "Condensing heat transfer coefficients for R134a at different saturation temperatures in inclined tubes," Proceedings of the ASME2013 Summer Heat Transfer Conference (HT 2013 17375), Minneapolis, MN, USA, 2013, pp. 1- 9.

[23] J.P. Meyer, J. Dirker and A.O. Adelaja, "Condensation heat transfer in smooth inclined tubes for R134a at different saturation temperatures," Int. J. Heat Mass Transf., 70, pp. 515-525, 2014.

[24] REFPROP., NIST thermodynamic properties of refrigerants and refrigerant mixtures (REFPROP), version 8.0, NIST Standard Reference Database 23, National Institute of Standards and Technology, Gaithersbury, MD. 2005.

[25] J. El Hajal, J.R. Thome and A. Cavallini, "Condensation in horizontal tubes. Part 1: two-phase pattern map," Int. J. Heat Mass Transf., vol. 46, pp. 3349 - 3363, 2003.

[26] D. Kim and A.J. Ghajar, "Heat transfer measurement and correlations for air-water flow of different flow patterns in a horizontal pipe," Exp. Therm. Fluid Sci., vol. 25, pp. 659-676, 2002.

[27] S.L. Kokal and J.F. Stanislav, "An experimental study of two-phase in slightly inclined pipes - 1. Flow pattern,” Chem. Eng. Sci., vol. 44 (3), pp. 665 - 679, 1989.

[28] H.M. Soliman, "On the annular-to-wavy flow pattern transition during condensation inside horizontal tubes," Can. J. Chem. Eng., vol. 60, pp. 475-481, 1982.

[29] M. Dobson and J. Chato, Condensation in smooth horizontal tubes, ASME J. Heat Transf., vol. 120, pp. 193213, 1998.

[30] M. Shah, "A general correlation for heat transfer during film condensation inside pipes," Int. J. Heat Mass Transf., 22, pp. 547-556, 1979.

[31] D. Jung, K. Song, Y. Cho, S. Kim, Flow condensation heat transfer coefficients of pure refrigerants, Int. J. Refrigeration, vol. 26, pp. 4-11, 2003.

[32] A. Cavallini, D. Del Col, L. Doretti, M. Matkovic, L. Rossetto, C., Zilio, G. Censi, "Condensation in horizontal smooth tubes: A new heat transfer model for heat exchanger design," Heat Trans. Eng., vol. 27, pp. 31-38, 2006. 